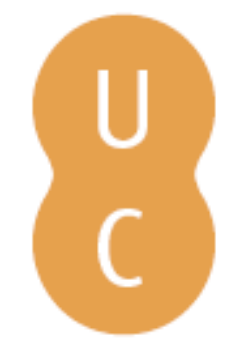

\title{
pommalina
}

\section{A receção do pensamento histórico de Ricoeur na historiografia portuguesa: Fátima Bonifácio e Fernando Catroga}

Autor(es): $\quad$ Soares, Martinho

Publicado por: Imprensa da Universidade de Coimbra

URL

persistente: URI:http://hdl.handle.net/10316.2/43632

DOI: $\quad$ DOI:https://doi.org/10.14195/978-989-26-1516-5_2

Accessed : $\quad$ 26-Apr-2023 07:53:53

A navegação consulta e descarregamento dos títulos inseridos nas Bibliotecas Digitais UC Digitalis, UC Pombalina e UC Impactum, pressupõem a aceitação plena e sem reservas dos Termos e Condições de Uso destas Bibliotecas Digitais, disponíveis em https://digitalis.uc.pt/pt-pt/termos.

Conforme exposto nos referidos Termos e Condições de Uso, o descarregamento de títulos de acesso restrito requer uma licença válida de autorização devendo o utilizador aceder ao(s) documento(s) a partir de um endereço de IP da instituição detentora da supramencionada licença.

Ao utilizador é apenas permitido o descarregamento para uso pessoal, pelo que o emprego do(s) título(s) descarregado(s) para outro fim, designadamente comercial, carece de autorização do respetivo autor ou editor da obra.

Na medida em que todas as obras da UC Digitalis se encontram protegidas pelo Código do Direito de Autor e Direitos Conexos e demais legislação aplicável, toda a cópia, parcial ou total, deste documento, nos casos em que é legalmente admitida, deverá conter ou fazer-se acompanhar por este aviso.

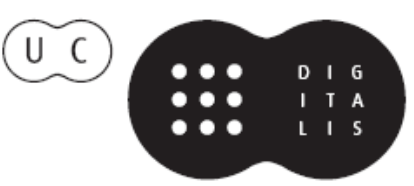


善商

Gonçalo Marcelo

César Correa Arias

Patrícia Lavelle

\#1

Tomás Domingo Moratalla COORDS.

A Atualidade

de Paul Ricour

numa Perspetiva

Ibero-Americana

Imprensa da Universidade de Coimbra

Coimbra University Press 
A Ricœuriana é uma série de livros (abrangendo monografias e volumes coletivos) disponibilizados em acesso aberto, dedicada à obra de Paul Ricœur e aberta a contribuições que também versem sobre outros autores e áreas, fomentando um permanente espírito de diálogo e interdisciplinaridade. As suas publicações abrangem diversos domínios da filosofia (estética, ética, fenomenologia, filosofia social e política, hermenêutica), mas também de disciplinas como os estudos literários, a história, a psicanálise, e a teologia, entre outras áreas relevantes para o pensamento de Ricœur. 


\section{A RECEÇÃO DO PENSAMENTO H ISTÓRICO DE RICAEUR NA HISTORIOGRAFIA PORTUGUESA: FÁtima BONIFÁCIO E FERNANDO CATROGA}

THE RECEPTION OF RICAEUR'S HISTORICAL THOUGHT in PORTUGUESE Historiography: FÁtima Bonifácio AND FERNANDO CATROGA

Martinho Soares Univ. Católica do Porto/CECH, Univ. de Coimbra ${ }^{1}$

Resumo: Neste estudo damos conta da receção do pensamento histórico-filosófico de Paul Ricœur em Portugal, designadamente em dois notáveis historiadores e epistemólogos da ciência histórica: Fátima Bonifácio e Fernando Catroga. O texto apresenta-se dividido em três secções principais. Depois de uma breve introdução, a primeira parte permite uma abordagem sucinta ao lugar da história na obra filosófica de Ricœur, as grandes problemáticas que perpassam pelos seus escritos e o seu impacto na epistemologia da história. A segunda secção consiste numa análise crítica à receção das meditações ricœurianas em torno do caráter narrativo da história na obra de

${ }^{1}$ Martinho Soares, Universidade Católica Portuguesa, Faculdade de Teologia, Rua Diogo Botelho 1327, 4169-005, Porto, Portugal. / CECH, Instituto de Estudos Clássicos, Largo da Porta Férrea, 3004-530 Coimbra, Portugal. Mail: martinhosoares@ gmail.com 
Fátima Bonifácio Apologia da História Política. A historiadora socorre-se da obra Temps et Récit sobretudo para escorar a sua apologia da história política. Independentemente da legitimidade da sua opção historiográfica, denotamos uma leitura parcial e conveniente. A terceira secção é dedicada à assimilação e transmissão do pensamento histórico ricœuriano em várias obras e artigos de teoria histórica da autoria de Fernando Catroga, leitor assíduo do filósofo francês. Concluímos confrontando a forma como os dois autores recebem e empregam a hermenêutica histórica de Paul Ricœur.

Palavras-chave: Fátima Bonifácio; Fernando Catroga; história; narrativa; Ricour.

Abstract: In this paper we give an account of the reception of the historical and philosophical thought of Paul Ricour in Portugal, namely in two conspicuous historians and epistemologists of the historical science: Fátima Bonifácio e Fernando Catroga. The text is divided into three main sections. After a short introduction, the first section gives one brief approach to the place of history in the Ricoeur's philosophical work, the main issues of their writings, and their impact in the epistemology of history. The second section consists in the critical analysis of the reception of Ricœur's thought concerning the link between narrative and history in Fátima Bonifácio's work Apology of the Political History. The Portuguese historian relies on Time and Narrative mostly to support her apology for the political history. The legitimacy of her historiographical option notwithstanding, we find this reading to be partial and convenient. The third section is devoted to the assimilation and transmission of Ricour's historical thought by Fernando Catroga in his many works and papers concerning historical theory. Catroga is a frequent reader of the French philosopher. 
We conclude by comparing the way the two authors receive and employ Paul Ricour's historical hermeneutics.

Keywords: Fátima Bonifácio; Fernando Catroga; history; narrative; Ricour.

\section{Introdução}

Não abundam em Portugal reflexões de caráter epistemológico sobre a ciência histórica. É, aliás, muito raro que os historiadores portugueses se consagrem a este tipo de meditações auto ou metarreflexivas sobre as suas práticas historiográficas, preferindo seguir escolas ou correntes vindas de fora, sobretudo de França, e as suas fundamentações metodológicas implícitas. ${ }^{2}$ Dentre o reduzido número dos que se devotam a esta tarefa mais filosófica do que histórica, sobressaem os dois intelectuais em foco neste capítulo: Fátima Bonifácio e Fernando Catroga. Fátima Bonifácio, porque entende ser seu dever justificar a escolha de um objeto e modo de estudo historiográfico que havia sido menosprezado, se

2 A despeito desta carência, existem alguns trabalhos dignos de menção. Salientamos o périplo cronológico da ciência histórica em Portugal ao longo dos séculos XIX e XX em Luís Reis Torgal, José Amado Mendes, e Fernando Catroga, História da História em Portugal. Sécs. XIX-XX, 2 vols., (Lisboa: Temas e debates, 1998). Com discursos genuinamente meta-históricos sobre o ofício do historiador ou que abordam questões de natureza epistemológica, apresentamos alguns títulos: Joaquim Barradas de Carvalho, Da História-Crónica à História-Ciência (Lisboa: Livros Horizonte, 1972); José M. Amado Mendes, A história como ciência: fontes, metodologia e teorização (Coimbra: Coimbra Editora, 1987); José Mattoso, A escrita da História. Teoria e métodos. (Lisboa: Editorial Estampa, 1997); Luís Reis Torgal "História, divulgação e ficção", in Luís Reis Torgal, José Amado Mendes, e Fernando Catroga, História da História em Portugal. Sécs. XIX-XX, vol. 2, (Lisboa: Temas e debates, 1998), 155-219; José Augusto França, História, que história? (Lisboa: Colibri, 1999); Rui Bebiano, "Sobre a história como poética", in José d'Encarnação (org.), As oficinas da história. (Lisboa: Colibri, 2000), 47-70. Para além disto, é de saudar vivamente a criação recente da primeira revista nacional dedicada a questões da natureza metodológica e epistemológica no âmbito historiográfico: revista online Práticas da História, in http://www.praticasdahistoria.pt/pt/. Já publicado o n. ${ }^{\circ} 1$ (2015), consultado a 29-01-2016. 
não mesmo repudiado, pelas grandes correntes historiográficas do século XX, incluindo no nosso país, e pugnar pela sua reabilitação. Falamos obviamente da história política ou factual, que ocupou quase todo o campo da historiografia até às primeiras décadas do século XX. Fernando Catroga, porque soma ao ofício de historiador o de pensador e teorizador da ciência histórica, por via da sua função de docente, tendo publicado vários livros sobre esta matéria. Como historiador, está mais próximo da Nova História francesa e do estudo das Ideias, embora não despreze nas suas investigações o facto político ou o modo narrativo, podendo, em coerência com a dialética ricœuriana, articular acontecimentos breves com estruturas de longa duração, para descrever, por exemplo, os costumes sociais relacionados com o culto tanatológico. ${ }^{3}$

Sobre a receção do pensamento e da obra de Paul Ricœur em Portugal, podemos dizer que não se fica atrás da de outros grandes filósofos da contemporaneidade, merecendo uma atenção considerável quer por parte da comunidade académica e científica portuguesa quer por parte do público instruído. Para isso concorre, grandemente, o facto de a sua obra ser extensa e polimática, fruto dos múltiplos diálogos que o filósofo foi capaz de estabelecer com outras ciências humanas e sociais. De facto, as teses de Ricœur encontram hoje admiradores em áreas do saber tão diversas, ou afinal tão complementares, como a Filosofia, o Direito, os Estudos Literários, a Psicologia e a Psicanálise, a História, a Teologia, a Ética e a Bioética, entre outras. Curiosamente, com uma pluralidade de assuntos tão profícua e ampla, um dos temas que menos eco tem tido na comunidade lusa é justamente o da hermenêutica histórica; ${ }^{4}$ isto a despeito

\footnotetext{
${ }^{3}$ Fernando Catroga, O Céu da memória. Cemitério romântico e culto dos mortos. (Coimbra: Minerva, 1999).

${ }^{4}$ Apresentámos em 2011, à Universidade de Coimbra, uma tese de doutoramento dedicada à análise crítica das reflexões de Ricœur sobre o tema da historiografia. Esta deu origem ao seguinte volume: Martinho Soares, História e Ficção em Paul
} 
de o filósofo, como adiante veremos, ter dado a esta questão um lugar de não pouca relevância, como se pode comprovar pela bibliografia publicada. Pensamos que os motivos desta fraca adesão estão justamente relacionados com a escassa produção epistemológica que acima denunciámos. Por força desta omissão, ganham ainda mais importância os preciosos contributos de Bonifácio e Catroga, que aqui nos propomos analisar, com a vantagem de serem ambos assimiladores da hermenêutica ricœuriana.

\section{I - O lugar da história na obra filosófica de Paul Ricœur}

Les historiens savent la dette qu'ils ont envers Paul Ricour... Le livre de Ricœur les a aidés à être plus lucides sur leur propre pratique et à comprendre comment l'intention de vérité qui fonde leur discipline ne pouvait être séparée des parentés qui lient son écriture à celle des récits de fiction. ${ }^{5}$

Paul Ricœur está entre os filósofos que na segunda metade do século XX mais se debruçou sobre questões de natureza histórico-epistemológica, com o intuito determinado de encontrar um lugar firme para a história entre as ciências sociais. Com esse fito, enfrentou as correntes e ideologias que puseram em causa o seu estatuto científico, a sua qualidade narrativa e até o seu valor ético: o

Ricœur e Tucídides. (Porto: Fundação Eng. António de Almeida, 2014). Ainda dentro desta temática, temos proferido diversas comunicações e publicámos: «Ekphrasis e enargeia na historiografia de Tucídides e no pensamento filosófico de Paul Ricœur», Talia Dixit 6 (2011). http://www1.unex.es/arengas/taliadixit6.htm

5 Roger Chartier, "Le passé au présent", in Le Débat 122 (2002): 4. Sobre o impacto das teses de Ricœur na historiografia francesa veja-se C. Delacroix, F. Dosse, P. Garcia, Les courants historiques en France, (Paris: Gallimard, 2007), 587-588. 
narrativismo e o estruturalismo, o positivismo lógico, o negacionismo. É inegável que a história ocupa um lugar de destaque na economia do pensamento ricœuriano. Para além de significativo número de artigos e ensaios, contam-se cinco obras com a hermenêutica histórica em destaque: Histoire et vérité (1955), Temps et récit I e III (1983 e 1985), Du texte à l'action: Essais d'herméneutique II (1986), La mémoire, l'histoire, l'oubli (2000).

Numa entrevista publicada na revista Esprit, em 1981, pouco antes do lançamento do primeiro volume de Temps et récit, Paul Ricœur justifica a sua opção pela história com três razões de ordem essencial e várias de ordem técnica. ${ }^{6}$

Em primeiro lugar, considera que não é possível uma filosofia sem diálogo com as ciências humanas e que a história ocupa um lugar fundamental no concerto das ciências humanas. Em seguida, afirma que não há conhecimento de si que não se efetue através do desvio por sinais, símbolos e obras culturais; entre estas obras culturais encontram-se de forma permanente as histórias que contamos e que o historiador escreve. Por fim, sublinha a necessidade de preservar a diversidade das formas de linguagem existentes - a Ricœur interessava, sobretudo, nesta altura, o caráter narrativo do ato de contar histórias, em ordem a uma poética do tempo.

As razões de ordem técnica prendem-se com várias questões interligadas. Desde logo, o desejo de superar a subdivisão paradoxal do ato de narrar entre história e ficção. Não haverá um fator de convergência, de unidade? Para Ricœur, a intriga é o elemento comum que une os dois géneros narrativos. Em segundo lugar, pareceu-lhe que este ato narrativo unificador tem uma relação privilegiada com a experiência humana do tempo, porquanto esta não é redutível ao tempo cronológico marcado pelos relógios. Daqui surge a bifurcação

\footnotetext{
${ }^{6}$ P. Kemp e F. Marchetti (redação), "L'histoire comme récit et comme pratique. Entretien avec Paul Ricœur", in Esprit 54 (1981):155-165.
} 
entre tempo cronológico e tempo histórico; se o segundo é o meio através do qual nós narramos, conclui-se o seguinte: "O caráter narrativo da experiência do tempo seria pois uma espécie de teste para articular filosoficamente a estrutura do tempo, o que sempre foi tido como um dos grandes problemas da filosofia". 7 Contra a opacidade e mudez da experiência temporal, Ricœur propõe a loquacidade da narrativa, que serve como uma "espécie de janela aberta sobre o que é o tempo humano". ${ }^{8}$

Finalmente, há ainda razões de uma terceira ordem, secundárias do ponto de vista filosófico mas centrais do ponto de vista das suas convicções pessoais. Ricœur recorda "o caráter essencialmente narrativo da fé bíblica, que, antes de se exprimir em dogmas, em expressões abstratas sobre Deus, se apoia em histórias contadas: a história do Êxodo, a história da Crucificação e da Ressurreição, a história do Pentecostes, da Igreja primitiva ...". ${ }^{9} \mathrm{O}$ ato narrativo possui, por conseguinte, uma dimensão religiosa que poderá estar relacionada com o potencial da narrativa para estruturar o tempo. Todavia, antes desta dimensão religiosa, existe uma dimensão ética na narrativa. Nenhuma existência pode viver sem história, nenhuma consciência humana é autotransparente ou autoposicional, porque toda a experiência está imbuída de temporalidade, e ninguém se pode conhecer a si próprio sem ser por intermédio das narrativas que conta sobre si, o que leva a falar de uma função identitária pessoal e comunitária da narrativa. ${ }^{10}$

\footnotetext{
${ }^{7}$ Idem, op. cit., 156 [tradução nossa].

8 Ibid.

9 Ibid.
}

10 “... notre propre existence est inséparable du récit que nous pouvons faire de nous-mêmes: les histoires, vraies ou fausses d'ailleurs - peu importe ! -, les fictions aussi bien que les histoires exactes, disons vérifiables, ont cette valeur de nous donner une identité. ... Si l'on applique cette idée au champ religieux, on peu dire qu'Israël a constitué son identité en racontant sa propre histoire. Certains auteurs ont même appelé la Bible l'autobiographie d'Israël. Et, en ce sens, on peut dire qu'une tradition religieuse se caractérise d'abord par les histoires qu'elle raconte 
Talvez não seja possível identificar um tema que possa unificar a ampla e heterogénea bibliografia ricouriana sobre a temática histórica, que conta com as obras axiais já referidas e uma panóplia de artigos, comunicações, entrevistas e ensaios dispersos por revistas, livros, enciclopédias e atas de colóquios. No âmbito da reflexão epistemológica, um dos tópicos mais recorrentes é a dialética explicação-compreensão, sob a qual se discute a relação da história com a ciência e a narrativa, e daí com o tempo, a memória e a ficção. $\mathrm{Na}$ área da reflexão hermenêutica, da ontologia e da filosofia da história, os escritos de Paul Ricœur versam sobre o sentido da história, da consciência histórica e da condição histórica do homem, da memória e do esquecimento. No entanto, parece-nos que a preocupação maior do autor nesta matéria como, de um modo geral, em toda a sua produção filosófica tem como cerne a compreensão do homem no seu meio a partir da sua ação: o que é o homem, o que (e de que forma) as "praxeis" culturais humanas (muito particularmente as mediadas pela linguagem simbólica-metafórica-narrativa) nos podem revelar acerca do agente e do paciente humano? Em última análise, é sempre o mistério do homem temporal, agente, falível e sofredor que o filósofo procura iluminar através da análise semântica dos elos simbólicos que medeiam a nossa relação com o mundo e connosco próprios. Neste processo interpretativo, as narrativas ocupam um lugar cimeiro: a narrativa diz de forma indireta (poética), mas significativa, o homem concreto e a realidade que o envolve. Ricour parte da constatação de que o homem vive enredado em histórias, procura conhecer-se e dar-se a conhecer através delas.

Compreende-se, pois, que a história - sendo, de um modo específico, uma narrativa e, além do mais, uma narrativa que visa relatar factos verdadeiros, comprováveis - ocupe um lugar central nesta

et, bien entendu aussi, par les interprétations symboliques ou autres qu'elle greffe sur ces histoires. Mais le premier noyau est un noyau narratif" (Ibid.). 
dinâmica. Que a história é uma narrativa comprova-o a própria ambiguidade do termo que na maior parte das línguas europeias significa, simultaneamente, o que realmente aconteceu no passado (dimensão ontológica do termo) e o discurso que sobre isso se faz (dimensão epistemológica do termo). ${ }^{11}$ Ricour acredita que esta ambiguidade semântica não acontece por acaso, contribuindo para reforçar a similitude entre o ato de narrar a história e o estar na história, ou seja, entre fazer a história e ser histórico. Vai ainda mais longe ao destacar o papel que história e ficção desempenham na construção de narrativas que direta e indiretamente contribuem para desfazer a opacidade da experiência humana. ${ }^{12}$ De facto, as histórias e a história são fautoras de historicidade humana. ${ }^{13}$ A polissemia da palavra história serve para recuperar o papel da narrativa na história, depois de um período de eclipse, ${ }^{14}$ obrigando o historiador a interrogar-se sobre o seu ato de escrita, sobre a proximidade deste com a ficção e ainda sobre a fronteira que os separa. ${ }^{15}$ Apesar de

11 Paul Ricœur, "Pour une théorie du discours narratif", in La narrativité, ed. D. Tiffeneau (Paris: Ed. du CNRS, 1980), 58.

12 “... la prétention référentielle indirecte des récits de fiction et la prétention référentielle directe des récits historiques (en tant qu'histoire 'vraie', au sens épistémologique du mot 'vrai')" (Ibid., 58)

13 "Cette opacité logique peut expliquer que l'historicité de l'expérience humaine ne puisse être portée au langage que comme narrativité, - et que cette narrativité elle-même ne requière pas moins que le jeu et l'intersection des deux grands modes narratifs. L'historicité est dite, dans la mesure où nous racontons des histoires et écrivons l'histoire." (Ibid., 59).

${ }_{14}$ Paul Ricœur, Temps et récit I: L'intrigue et le récit historique, (Paris : Seuil, 1983), 171-216: "L'éclipse du récit".

15 "Après une longue éclipse du récit au cours de laquelle les historiens du $\mathrm{XIX}^{\mathrm{e}}$ et $\mathrm{du} \mathrm{XX}^{\mathrm{e}}$ siècle ont cru pouvoir fonder une physique sociale, croyant rompre à jamais avec l'histoire-récit, les historiens aujourd'hui insistent au contraire sur le fait que la notion d'histoire revêt une valeur polysémique, désignant tout à la fois l'action narrée et la narration elle-même, confondant tout ainsi l'action d'un narrateur, qui n'est pas forcément l'auteur, avec l'objet du récit. L'historien est de nouveau invité à s'interroger sur son acte d'écriture, sur la proximité de celui-ci avec l'écriture fictionnelle et en même temps sur la frontière qui distingue les deux domaines". (François Dosse, "Le moment Ricœur de l'opération historiographique", Vingtième siècle, Revue d'histoire 69 (2001): 87). 
reconhecer essa polissemia do termo história, que tanto pode significar história como histórias, o filósofo francês acentua as diferenças que separam a história das narrativas ficcionais, nomeadamente no que à pretensão à verdade diz respeito. É que a imaginação não está confrontada com as mesmas exigências críticas e científicas da história, sendo que esta se pauta pela realidade dos documentos e dos arquivos. ${ }^{16}$

A suspeita de que a história não é totalmente verdadeira porque está enredada na ficção nasceu com a própria história e acompanhou-a ao longo dos séculos. Contudo, foi a partir do século XIX, com o eclodir da chamada história científica (epifenómeno do hegemónico e otimista modelo positivista), que a questão se agudizou e ganhou novos contornos. Para a história exigiu-se o mesmo tipo de método e resultados que as ciências físicas e biológicas almejam (Montesquieu, Voltaire, Condorcet). No entanto, a conclusão de que a lei e a causa positivista não estavam ao alcance da história não fez os historiadores arredarem pé da senda das ciências, já não das naturais mas das sociais e humanas. Enquanto teóricos narrativistas e estruturalistas tentaram aproximar a história da narrativa, acentuando a sua dimensão de artefacto literário, sujeito ao relativismo de todo o discurso ficcional, os historiadores franceses da entourage dos Annales e os teóricos do modelo nomológico procuraram afastar a

16 "Je n'ai aucunement l'intention de nier ou d'obscurcir les différences évidentes qui séparent l'histoire de l'ensemble des récits de fiction quant à leur prétention respective à la vérité. Pour un certain niveau d'analyse et d'argumentation, le concept conventionnel de vérité, défini en termes de vérification et de falsification empiriques, est parfaitement valide. ... la vérification ou la falsification en histoire ne met pas en jeu un concept de vérité différent de celui que la physique assume. Documents et archives sont les sources de vérification et de falsification pour l'investigation historique. Les récits de fiction, d'autre part, ignorent la charge de fournir des preuves de cette sorte.... il reste que l'imagination ignore le dur labeur de se confronter à des documents et même de les établir en fonction des questions qui leur sont posées. En ce sens l'imagination n'a pas de 'faits' à traiter". (Paul Ricœur, "Pour une théorie du discours narratif", in La narrativité, ed. D. Tiffeneau (Paris: Ed. du CNRS, 1980): 151). 
história da narrativa e do acontecimento breve, aproximando-a das ciências exatas. A história é confrontada com a alternativa de ser ciência idiográfica (compreensiva) ou ciência nomotética (explicativa), narrativa de acontecimentos singulares ou conjunto de proposições científicas que inscrevem factos sob leis gerais.

É neste cenário de real tensão que surgem as reflexões de Ricœur. Homem atento às questões do seu tempo, leitor assíduo dos historiadores, contribuiu de forma determinante para uma conciliação. A sua grande vitória foi justamente a de ter conseguido congraçar dois conceitos aparentemente contraditórios sem retirar credibilidade e autoridade explicativa à história. Esta, apesar de recorrer à ficção para cativar o público leitor, para dar visibilidade aos factos narrados, em suma, para se dar a ler, continua a ter como alvo insubstituível a verdade. Não uma verdade de teor positivista (em que haveria coincidência entre o real e o conhecimento histórico), mas a verdade visada através da positividade do ter-sido e reconstruída sob o regime analógico da representância [représentance] ${ }^{17}$ Só assim a história mantém a capacidade para dar conta, de forma científica, de uma realidade exterior ao discurso, evitando cair no relativismo que os teóricos do linguistic turn alimentaram.

Atualmente, é relativamente pacífica entre historiadores e filósofos a admissão da componente ficcional da história em concomitância com a autonomia explicativa e científica da mesma. É reconhecido o contributo de Ricœur para este processo. ${ }^{18}$ A história é uma ciência,

\footnotetext{
17 Paul Ricœur, Temps et récit III : Le temps raconté, (Paris: Seuil, 1985), 252-283; Idem, La mémoire, l'histoire, l'oubli (Paris : Seuil, 2000), 359-369.

18 "Le tournant interprétatif adopté par les travaux actuels permet de ne pas se laisser enfermer dans la fausse alternative entre une scientificité qui renverrait à un schéma monocausal organisateur et une dérive esthétisante. Le basculement est particulièrement spectaculaire dans la discipline historique qui a été nourrie tout au long des années soixante et soixante-dix, sous l'impulsion de l'école des Annales, d'un idéal scientiste, celui de trouver la vérité ultime au bout des courbes statistiques et des grands équilibres immobiles et quantifiés. Grâce au travail sur le temps de Paul Ricœur, on redécouvre la double dimension de l'histoire qui, sous
} 
ainda que não como as outras, e uma arte, ainda que diferente de todas as outras. ${ }^{19}$ A ficção, sabemo-lo, é do domínio da criação, da modelação, do recurso à imaginação; tem contacto com o mundo, mas não tem contrato com a verdade factual nem está obrigada a prestar provas das suas declarações. A opinião de Ricœur é de que a história, ainda que não possa dispensar a imaginação, a interpretação e a retórica, é um discurso que, por meio de um método científico e crítico, busca incessante e incansavelmente a verdade rigorosa dos factos que narra, nisso ocupando um espaço distinto do da ficção. O historiador estabelece implicitamente com o leitor um compromisso ético e profissional de verdade, que implica julgar/ explicar mediante a apresentação de provas. E, nesse sentido, a sua tarefa aproxima-se da do juiz. ${ }^{20}$

Começámos este estudo com uma epígrafe alusiva à dívida que os historiadores franceses sentem para com Ricœur, movidos pelas suas pertinentes e valiosas reflexões epistemológicas sobre a historiografia. É nosso intuito agora dar nota da forma como as teses da história de Paul Ricœur foram recebidas por historiadores portugueses, nomeadamente nos dois que mais longamente se detiveram e absorveram as suas lições.

le même vocable en France, recouvre à la fois la narration elle-même et l'action narrée". (François Dosse, L'histoire, (Paris: Armand Colin, 2001), 54-55). Vide também C. Delacroix, F. Dosse, P. Garcia, Les courants historiques en France (Paris: Gallimard, 2007), 587-588.

19 Vide Jacques Le Goff, "História", in Enciclopédia Einaudi, Vol. 1: Memória-História (Porto: INCM, 1984), 158-259.

${ }^{20}$ A comparação do historiador com o juiz é muito frequente em P. Ricœur. Para além de várias menções em Temps et Récit, o autor dedica uma análise mais demorada ao tema em La mémoire, l'histoire, l'oubli. (Paris: Seuil, 2000) - "L'historien et le juge": 413-436. O grande historiador Carlo Ginzburg publicou também um ensaio sobre o mesmo assunto: Il giudice e lo storico (Turin: Einaudi, 1991). 


\section{II - A apologia da história política em Fátima Bonifácio}

Apologia da História Politica é o nome do ensaio que abre a obra com o mesmo título de Fátima Bonifácio, publicada em 1999 pela editora Quetzal. O corpo do livro compreende ainda três estudos de história política do século XIX, ilustradores práticos da teoria antes exposta. A autora, reputada historiadora e professora universitária, foi uma das poucas figuras do Portugal contemporâneo a produzir reflexão epistemológica e metodológica sobre história política e narrativa, sendo nesse exercício recetora e comentadora da trilogia Temps et Récit de Paul Ricour, obra de que se socorre frequentemente para estribar a sua argumentação. O seu texto surge no seguimento de um pequeno artigo de viragem publicado na revista Análise Social XXVIII (1993-3. '): 623-630, com o título "O abençoado retorno da velha história".

A Apologia da História Política tem o seu propósito bem definido no título: pretende demonstrar a pertinência, a validade e a dignidade $^{21}$ da história política como campo de estudo e disciplina literária, tal como era praticada antes de ter sido banida pela história-ciência instaurada pela Escola dos Annales. Trata-se de legitimar a história política tradicional, também conhecida como metódica, evenemencial, ou de batalha, e os seus objetos de eleição: "a política, as grandes figuras, as instituições, a história do pensamento e das ideias, a diplomacia e as relações internacionais, a história militar e constitucional". ${ }^{22}$ Note-se que foi a contestação a estes objetos privilegiados da pesquisa histórica que conduziu a Escola dos Annales àquilo que Ricœur designou por "eclipse da narrativa", resultado do abandono da história política em função de novos objetos de estudo

${ }^{21}$ Fátima Bonifácio, Apologia da história política (Lisboa: Quetzal, 1999), 20.

22 Fátima Bonifácio, "O abençoado retorno da velha história”, in Análise Social XXVIII, (1993-3. $\left.{ }^{\circ}\right): 628$. 
e do alargamento do questionário a dimensões socioeconómicas, ligadas às massas sociais e já não a indivíduos particulares, a factos e a datas. ${ }^{23}$ Pois bem, Fátima Bonifácio pretende deseclipsar a narrativa, reinvestindo-a do seu estatuto científico objetivo e racional, configurador de identidades e ações humanas passadas, e afastar da narrativa histórica tudo o que sejam trends seculares, séries de preços, padrões demográficos, evoluções estruturais, modos de produção, isto é, a ciência social. Não que menospreze o valor destas informações, apenas as remete para o campo das Ciências Sociais.

A sua tese compreende um preâmbulo e três andamentos. No preâmbulo é bem patente a crítica severa à história estrutural e de longa-duração implementada por Braudel e seus seguidores. Lamenta-se a autora pela perda do sujeito, das ações humanas e dos acontecimentos que delas resultam como fonte de inteligibilidade histórica, para dar lugar às estruturas profundas do fenómeno social.

$\mathrm{Na}$ primeira parte do ensaio, analisa os impasses da história como ciência, tentando desmascarar as suas pretensões científicas de âmbito nomológico. O seu ataque dirige-se de modo particular à Escola dos Annales, desde a fundação à sua terceira vaga, a da chamada Nova História ou História das Mentalidades. Mantendo um registo por vezes irónico e retórico próprio da diatribe, a historiadora, mostrando-se muito segura e convicta na argumentação e bem apoiada nas provas bibliográficas, prossegue o seu libelo contra a história económica e social, estrutural e das ideias, acusando-a de ter erradicado do campo da historiografia a sua matriz fundadora e identitária, a história política, e a sua forma natural, a narrativa. O suposto retorno da "nova história política", objeto da segunda

23 Justamente, em Temps et Récit I (Paris: Seuil, 1983), 183-184, Ricœur observa que história política, história factual e história-narrativa foram tomadas como expressões quase sinónimas e critica este tratamento depreciativo da categoria narrativa da história como efeito secundário de uma reação violenta contra a história dita política, à qual foi associada a narrativa. 
parte do ensaio, não serve de desagravo nem de compensação, pois que esta dita "nova história política", na ótica da autora, nada tem de político, continuando a repudiar como insignificantes a narrativa, o acontecimento breve, os grandes homens. Em muitos casos - denuncia a mesma - "não se deixa distinguir de outras disciplinas das ciências sociais como a politologia, a semiótica e a sociologia". 24 Evocando os principais artigos impulsionadores dos "retornos", desde o célebre e liminar texto que Lawrence Stone deu à estampa em 1979, "The return of Narrative" 25 , também citado por Ricœur na página 312 de La mémoire, l'histoire, l'oubli, até às reflexões autocríticas da própria Escola dos Annales, conhecidas como tournant critique, ${ }^{26}$ a partir de finais da década de 80 , e apelando a um ressurgimento da narrativa, a autora pretende pôr a nu a falácia do retorno. Destaca o contributo de Roger Chartier, o qual, apoiando-se nas teses de Paul Ricœur expostas em Temps et Récit, tenta demonstrar, na esteira do filósofo francês, que a história não chegou a perder totalmente a sua ligação à narrativa. ${ }^{27} \mathrm{~A}$ autora discorda, considerando que esta suposta nova história narrativa está muito longe da narrativa clássica como a definiu Ricour, com base nas teses de Danto, a saber, um realinhamento retrospetivo de acontecimentos passados provocados por agentes humanos e interpretados pelo historiador à luz de acontecimentos ulteriores relacionados com os primeiros. ${ }^{28}$ No seu entender: "'a nova história narrativa' não conta uma história. A história da França de Zeldin, ou a história de Montaillou de

\footnotetext{
${ }^{24}$ Fátima Bonifácio, Apologia da história política (Lisboa: Quetzal, 1999), 35.

25 Lawrence Stone, "The return of Narrative", in Past \& Present 85 (1979): 116-142 .

26 Vide C. Delacroix, F. Dosse, P. Garcia, Les courants historiques en France (Paris: Gallimard, 2007), 516-517.

${ }^{27}$ Roger Chartier, "L'histoire aujourd'hui: doutes, défis, propositions", in $A$ história a debate vol. I, ed. Carlos Barros (Santiago de Compostela, 1995): 119-130.

${ }^{28}$ Fátima Bonifácio, Apologia da história política (Lisboa: Quetzal, 1999), 62. Cf. Paul Ricœur, Temps et Récit I (Paris: Seuil, 1983), 256-265.
} 
Ladurie, ou a história da morte de Ariés, ou a história do medo de Delumeau, não contam propriamente algo que reconheçamos como uma história - em alguns casos nem há história nenhuma”. ${ }^{29}$

Mesmo a micro-história, que Ricour, em La mémoire, l'bistoire, l'oubli (obra publicada posteriormente ao ensaio de Fátima Bonifácio), considera ter recuperado a narrativa para o campo da historiografia, não colhe as graças da historiadora, considerando esta que a mudança de escala de macro para micro e a fixação num indivíduo particular, representante de toda uma comunidade, época, ou ideologia, continua refém da descrição e do social.

No terceiro andamento do seu ensaio, a autora explica, com base maioritariamente nas teses de Ricœur, o que considera ser uma verdadeira história política narrativa. Começa por reestabelecer como núcleo fundamental da história a compreensão empática ou simpatia intuitiva prenunciada em Giambattista Vico, apropriada pelo historicismo alemão, com reflexos significativos na sociologia compreensiva de Max Weber e daí na obra do pensador e historiador francês Raymond Aron. Refazendo o percurso histórico-filosófico também percorrido por Ricœur em Temps et Récit, Fátima Bonifácio evoca o modelo nomológico da história, advogado por K. Popper e C. G. Hempel, e os seus críticos narrativistas, William Dray, Paul Veyne, Arthur Danto. Expondo o confronto entre as duas fações, coloca-se como seria expectável do lado dos narrativistas e dos defensores da sociologia compreensiva. Interessa-lhe sobremaneira fundamentar a compreensão narrativa e a imputação causal singular como método inteligível específico e único do discurso histórico, e logo da história política, a seu ver, a única possível e verdadeira. Em seu auxílio, convoca novamente a definição de história que Ricœur formula a partir do conceito de frase narrativa de Arthur Danto, a saber: "a história é uma descrição de acontecimentos anteriores sob

${ }^{29}$ Fátima Bonifácio, Apologia da bistória política (Lisboa: Quetzal, 1999), 62. 
a descrição de acontecimentos ulteriores, desconhecidos dos atores dos primeiros" ${ }^{30}$ Daí em diante toma o filósofo francês como o seu "principal guia", mas com as devidas ressalvas: "muito embora eu me guie a mim mesma num sentido diferente daquele em que ele [Ricour] pretende conduzir o leitor". ${ }^{31}$ A autora alude aqui ao facto de a reflexão de Ricœur se encaminhar para uma poética do tempo, investindo a narrativa histórica e ficcional como solução poética à aporia do tempo.

Bonifácio toma como ponto de partida a asserção ricœuriana de que entre a Nova História, mesmo a mais fundamentalista, e a narrativa existe um vínculo, seja ele ténue ou indireto, mas essencial para preservar o caráter propriamente histórico da história. Evoca, em seguida, a conhecida tese defendida por Ricœur da dimensão configurante da narrativa enquanto síntese do heterogéneo, relembrando a capacidade que esta tem de convocar em simultâneo causas heterogéneas e reuni-las num todo coeso e inteligível. Deste modo, a narrativa "dá-nos uma visão global dos acontecimentos, quer dizer, permite-nos 'apreendê-los juntos' através de uma espécie de 'juízo sinótico' que abarca, 'num único ato mental', coisas separadas no tempo e no espaço, e até separadas de um ponto de vista lógico". 32 Daqui passa a concluir que "a narrativa constitui a forma natural da explicação histórica, querendo com isso dizer que narrar e explicar se não distinguem". ${ }^{33}$ Acrescenta que Ricœur "vai ainda mais longe e afirma que 'uma narrativa que fracassa em explicar é menos do que uma narrativa'. Daí que explicar melhor consista simplesmente em narrar mais". ${ }^{34}$ Esta última afirmação, apresentada como corolário

\footnotetext{
30 Idem, op. cit., 110.

${ }^{31}$ Idem, op. cit., 115.

${ }^{32 I}$ dem, op. cit., 116.

33 Idem, op. cit., 120.

${ }^{34}$ Ibid.
} 
da sua argumentação, se pretende ser a tradução da famosa sentença "en expliquant plus on raconte mieux" 35 ou de uma sua similar que Ricœur colhe em Paul Veyne, "Expliquer plus c'est comprendre mieux"36 exige da nossa parte crítica e correção. Há uma divergência significativa entre o modo como Veyne e Bonifácio de um lado e Ricœur do outro entendem a asserção. Na verdade, nunca foi intenção de Ricœur considerar autossuficiente a explicação narrativa, a ponto de esta poder dispensar uma explicação de teor nomológico. De facto, Ricœur perfilha a ideia dos narrativistas de que narrar já é explicar. O famoso conceito aristotélico do "um por causa do outro" (di'allela), em vez de um a seguir ao outro, próprio da crónica, faz a conexão lógica de qualquer intriga. O filósofo francês também reconhece às teses narrativistas da história a virtude de chamar a atenção para o facto de a qualidade propriamente histórica da história só poder ser preservada por meio do elo que liga a explicação histórica à compreensão narrativa, contra a rutura epistemológica que pretendeu dissociá-las. Todavia, afasta-se dos narrativistas por estes contemplarem apenas as formas historiográficas com ligação direta e visível à narrativa, ignorando as transformações que a historiografia foi sofrendo ao longo do século XX; 37 ou por não conseguirem integrar a explicação através de leis no tecido narrativo da história. Esta crítica aplica-se perfeitamente ao ensaio de Fátima Bonifácio, o qual podemos classificar categoricamente de narrativista, defendendo a narrativa como única "estratégia de explicação na qual ficam subsumidas a teoria, a análise e a demonstração". ${ }^{38}$ Para a historiadora

\footnotetext{
35 Paul Ricour, Du text à l'action: Essais d'herméneutique II (Paris: Seuil, 1986), 15.

36 Paul Ricœur, Temps et Récit II (Paris: Seuil, 1984), 14. Cf. Paul Veyne, Comment on écrit l'bistoire, (Paris : Seuil, 1971), 132.

${ }^{37}$ Ricœur é desde o início muito assertivo e cauteloso nesta matéria: "ma thèse concernant le caractère ultimement narratif de l'histoire ne se confond aucunement avec la defense de l'histoire narrative" (Paul Ricœur, Temps et Récit I (Paris: Seuil, 1983), 165). O itálico é do próprio autor.
}

38 Fátima Bonifácio, Apologia da história política (Lisboa: Quetzal, 1999), 50. 
não há como conciliar narrativa e ciência nomotética. Alguns dos seus pares criticaram-na justamente por verem nesta sua Apologia o retorno da velha história política tal como se fazia em finais do século XIX. ${ }^{39}$ A própria não refutaria essa objeção. E embora conceda, na esteira de Ricour, que a narrativa histórica incorpore elementos heterogéneos de ordem estrutural, descritiva ou não evenemencial entre o relato dos acontecimentos, tal deve ser feito em proporção que não quebre a unidade dramática ou a coesão narrativa, aludindo aos preceitos que Aristóteles preconiza na Poética para o modelo trágico. ${ }^{40}$ Com estas restrições, torna-se muito difícil aceitar como narrativos a maioria dos trabalhos historiográficos produzidos ao longo do século XX até à atualidade, cuja natureza narrativa Ricœur nunca pôs em causa, embora tivesse considerado muitos no limiar da sociologia e em risco de apagar a identidade da história enquanto ciência social e humana autónoma.

O filósofo francês nunca pretendeu denegar o caráter científico da história nem excluí-la do campo das ciências sociais e humanas; pelo contrário, trabalhou no sentido de marcar a sua especificidade, pela sua ligação umbilical à narrativa e desta ao acontecimento temporal - peça fundamental sem a qual não existe narrativa. Este facto leva-o, como bem viu Fátima Bonifácio, a fazer uma revisão crítica do contributo da escola francesa dos Annales, da sua repugnância pelo acontecimento breve e, consequentemente, pela narrativa, bem como

\footnotetext{
39 Vide Luís Reis Torgal, José Amado Mendes, e Fernando Catroga, História da História em Portugal. Sécs. XIX-XX, vol. 2. (Lisboa: Temas e debates, 1998), 69. O seu colega historiador, Nuno Severiano Teixeira, também aborda a temática em "A história política na historiografia contemporânea", publicado na revista Ler História 13, (1998): 77-102. Não obstante, este procura conciliar a nova história política com a história social e a própria sociologia, uma solução inteiramente consentânea com a visão de Paul Ricœur, o qual defende que a compreensão histórica pode e deve recorrer às explicações científicas das outras ciências sociais, mais gerais mas irmãs, como a sociologia, a antropologia, a demografia, para aclarar os factos particulares por ela narrados.
}

40 Fátima Bonifácio, Apologia da história política (Lisboa: Quetzal, 1999), 125. 
do modelo nomológico, que tenta inscrever a história no círculo fechado das ciências exatas. É verdade que estas teorias da história conduziram ao abandono da história política e factual, substituída que foi por uma história de longa duração, tornada história social, económica, cultural, mas que, segundo Ricœur, permanece unida ao tempo e dá conta de acontecimentos que ligam uma situação inicial a uma situação final, pois não é a velocidade da mudança que faz a história. ${ }^{41}$

Neste sentido, um dos passos mais ousados e também mais admiráveis de Ricœur é a arguta e paciente análise da extensa obra histórica de F. Braudel, La Méditerranée et le Monde méditerranéen à l'époque de Philippe II (publicada em 1949), no intuito de fazer emergir da sua estrutura tripartida as características de uma intriga.

Ignorar a inteligibilidade de base da narrativa (a sua capacidade configuradora) impede de compreender como é que a explicação histórica se pode coadunar com a compreensão narrativa, de maneira que: "en expliquant plus on raconte mieux". ${ }^{42}$ É este famoso adágio que nos oferece como solução à antinomia explicação-compreensão. Ele serve de divisa aos estudos desenvolvidos pelo autor em Temps et récit I e II, onde se trata de ligar explicação e compreensão ao nível, respetivamente, da historiografia e da ficção, mas assoma já nos estudos hermenêuticos que encontramos reunidos em $D u$ texte à l'action: Essais d'herméneutique II. Apesar de as análises de

41 "La vitesse du changement ne fait rien à l'affaire. En restant liée au temps et au changement, elle reste liée à l'action des hommes qui, selon le mot de Marx, font l'histoire dans des circonstances qu'ils n'ont pas faites. Directement ou indirectement, l'histoire est celle des hommes qui sont les porteurs, les agents et les victimes des forces, des institutions, des fonctions, des structures dans lesquelles ils sont insérés. A titre ultime, l'histoire ne peut rompre tout à fait avec le récit, parce qu'elle ne peut rompre avec l'action qui implique des agents, des buts, des circonstances, des interactions et des résultats voulus et non voulus. Or l'intrigue est l'unité narrative de base qui compose ces ingrédients hétérogènes dans une totalité intelligible". (Paul Ricœur, Du texte à l'action: Essais d'herméneutique II (Paris: Seuil, 1986), 15).

42 Ibid. 
Temps et récit serem mais detalhadas, ambas as obras convergem na finalidade. No que à história diz respeito, Ricœur não nega que esta possa recorrer a leis, que pode pedir emprestadas a outras ciências sociais mais sofisticadas como a demografia, a economia, a linguística, a sociologia ou que a explicação histórica possa ser constituída por leis, causas regulares, funções, estruturas; questiona, sim, o seu funcionamento, o facto de não funcionarem em história da mesma maneira que funcionam nas ciências da natureza, e terem de se articular necessariamente com a compreensão narrativa que lhes subjaz. As leis só por si não têm significado histórico, para o adquirirem têm de estar inseridas numa narração de acontecimentos aos quais se referem, pois é a compreensão narrativa que preserva o caráter irredutivelmente histórico da história. De facto, observa Ricœur, o historiador não estabelece as leis, utiliza-as. ${ }^{43}$

Esta dialética entre compreensão e explicação é ignorada por Fátima Bonifácio, essencialmente - podemos conjeturar nós - porque a sua aceitação inviabilizaria o seu dogmatismo narrativista e político, que pretende fazer à ciência social o que a Escola dos Annales fez à narrativa. Do mesmo modo que a história estrutural socioeconómica francesa entendeu erradicar da escrita historiográfica qualquer intriga, para a transformar numa sequência de dados científicos, a mais das vezes quantitativos, também Bonifácio pretende expurgar da história política todo o dado científico geral, proveniente das outras ciências sociais, porquanto afetaria a unidade narrativa, entendida esta no seu sentido clássico, promanado da Poética aristotélica. No fundo, a grande preocupação de Bonifácio consiste na preservação a qualquer custo da narrativa e da intriga histórica tradicionais. Compreende-se, por conseguinte, a preferência pelo facto político-militar, o único passível de uma configuração narra-

43 Paul Ricour, "Pour une théorie du discours narratif", in La narrativité, ed. D. Tiffeneau (Paris: Ed. du CNRS, 1980), 7. 
tiva linear. Esta posição estremada vai contra o espírito dialético e conciliador de Ricœur. No entanto, a mesma dialética encontra noutro historiador e académico português um bom acolhimento, de que falaremos a seguir.

\section{III - Ricour lido por Fernando Catroga}

Fernando Catroga é um historiador e destacado pensador da teoria da história, conjugando o ofício de investigador e divulgador de História das Ideias, da Cultura e das Mentalidades com o de professor de Teoria da História e do Conhecimento Histórico, na Faculdade de Letras da Universidade de Coimbra. Autor de várias obras historiográficas e outras tantas de filosofias da história e da memória, é nestas últimas que o pensamento histórico-filosófico de Ricœur assoma de forma bastante significativa, demonstrando o quanto o historiador conimbricense é um leitor atento do filósofo francês. Também nas suas aulas o nome de Ricœur é frequentemente invocado, como se pode comprovar no texto das suas provas de agregação, relatório curricular da cadeira que leciona. ${ }^{44}$

Memória, História e Historiografia, opúsculo dado ao prelo em 2001, resulta da compilação de três notáveis ensaios: "Recordação e esquecimento"; "Memória e historiografia"; e o terceiro, muito breve, "Comemoração e poder". Ricœur é presença assídua ao longo de todo o primeiro e segundo ensaios entre outros destacáveis teorizadores da memória, alguns destes citados a partir da obra do filósofo francês. Dele menciona Catroga vários artigos e a obra La Mémoire, l'histoire, l'oubli, publicada pouco antes do seu livro. Os artigos de Ricœur, no total de quatro, surgiram inicialmente em várias revistas

${ }^{44}$ Fernando Catroga, Teoria da História e do Conbecimento Histórico - Relatório, Universidade de Coimbra, Faculdade de Letras, 1996 (edição policopiada). 
em França e em Espanha, e constituem textos embrionários das teses expostas posteriormente em La mémoire, l'histoire, l'oubli, acabando por se incorporarem de forma diluída na própria obra. ${ }^{45}$

Os passos do homem como restolho do tempo. Memória e fim do fim da história, publicado em 2009, em edição da Almedina, retoma os três ensaios referidos, em versão revista e aumentada, aos quais se juntam uma série de outros estudos, alguns reconduzidos a partir de revistas, outros da obra anterior, Caminhos do Fim da História (2003). ${ }^{46} \mathrm{Em}$ boa verdade, o volume de 2009 funciona como uma espécie de ponto de chegada de todo um percurso académico e intelectual consagrado à reflexão historiográfica. A influência de Ricœur é aqui notória, servindo as suas próprias ideias bem como a de outros autores reunidos de forma eclética nos seus textos, como Halbwachs, Bergson, M. de Certeau, F. Hartog, R. Koselleck, Santo Agostinho, Aristóteles e Platão ou que refletiram sobre e com base na sua obra, casos de Jeffrey Barash e François Dosse. Todos encontram em Catroga uma autêntica caixa-de-ressonância, que não se limita, muito longe disso, à mera paráfrase. Tendo como pano de fundo o trabalho intelectual destes e de outros como M. Augé, Le Goff, S. Mosès, I. Berlin, H. Arendt, T. Todorov, W. Benjamin, M. Bloch, Durkheim, Hegel, Catroga expõe as suas, por vezes, intrincadas leituras com perspicácia e originalidade, não se limitando

45 São eles: "Entre mémoire et histoire", Projet 248 (1996): 7-16; "Vulnerabilité de la mémoire", in Patrimoine et passions identitaires. Entretiens du patrimoine. Théâtre National de Chaïlot, Paris, 6, 7 et 8 Janvier, 1997, ed. Jacques Le Goff et al., (Paris: Fayard, 1998); La Lectura del tiempo passado: memoria y olvido, (Madrid: Ediciones de la Universidad Autonoma de Madrid, 1998); "Un parcours philosophique", in Magazin Littéraire 390, (Septembre, 2000).

${ }^{46}$ Fernando Catroga, Caminhos do Fim da história, (Coimbra: Quarteto, 2003). Nesta obra há apenas esparsas referências explícitas a Ricœur, mas adivinha-se muitas vezes o seu pensamento em pano de fundo, nomeadamente quando o autor aborda as temáticas do tempo, ou a relação entre história e ciência, a partir da dialética compreensão/explicação. A demonstrar a influência de Ricœur está o facto de o autor citar-lhe várias obras na bibliografia final: Temps et récit, 3 vols.; La mémoire, l'bistoire, l'oubli e La lectura del tiempo passado. Memoria y olvido. 
ao exposto pelo filósofo francês, mas demonstrando uma aptidão muito ricœuriana de pôr em diálogo à volta do mesmo assunto uma plêiade intelectual assaz heterogénea, quer nas ideias quer nas áreas científicas.

A figura tutelar de Ricœur é particularmente relevante nas duas primeiras partes da obra, onde se reflete acerca de memória, historiografia, morte, tempo, alteridade e epistemologia. A obra de referência continua a ser La mémoire, l'histoire, l'oubli, mas à colação vêm também Histoire et vérité, a trilogia Temps et récit $\mathrm{e}$ os artigos já referidos anteriormente. ${ }^{47} \mathrm{O}$ autor recupera temas ricœurianos como a dialética entre recordação e esquecimento, as teorias platónica e aristotélica sobre a memória como representação (eikon) do passado, o binómio aristotélico mneme e anamnesis, o traço como testemunho e indício e a relação destes com o documento, a importância do questionário, a memória como narrativa e ipseidade, os abusos da memória e da comemoração, a escrita da história como mediação com o passado, os três estádios da operação historiográfica definidos por Certeau ${ }^{48}$ e retomados por Ricœur, e a história como representância ou, como gosta de lhe chamar Catroga, re-presentificação de um referente ausente. Transcrevemos um passo sintomático da forma como o historiador conimbricense perfilha assumidamente uma meditação ricœuriana, por sua vez apoiada em Michel de Certeau - também ele aqui muito citado -, a da poética da ausência, para suavemente introduzir um tema da sua eleição como historiador das ideias: o papel dos cemitérios e do culto dos mortos nas sociedades ocidentais. ${ }^{49}$

\footnotetext{
47 Ver nota 45 supra.

48 Michel de Certeau, L'écriture de l'histoire (Paris: Gallimard, 1975).

49 Fernando Catroga, o céu da memória. Cemitério romântico e culto cívico dos mortos (Coimbra: Minerva, 1999).
} 
... são conhecidas e pertinentes as posições que Ricœur tomou na contenda: para ele, a memória e a história (incluindo a historiografia) mantêm uma relação que, na perspetiva da inevitável presença de horizontes de pré-compreensão no questionamento historiográfico, consente pôr-se "la mémoire comme matrice de l'histoire" (Paul Ricœur, 2000).

Propendemos para concordar com os que sustentam esta tese. E se outras razões não houvesse, bastaria ir ao encontro da raiz de onde nasce a necessidade de recordar para a perfilharmos, a saber: a experiência humana de domesticar os mortos através do culto tanatológico. E, por mais estranho que à primeira vista possa parecer às leituras pouco sensíveis ao simbólico, a escrita da história também é, à sua maneira, "um gesto de sepultura". Com efeito, as narrações do passado são equiparáveis à linguagem dos cemitérios nas povoações, porque procuram "re-presentar [ou, dizemos nós, re-presentificar] mortos através de um itinerário narrativo" (Michel de Certeau, 1975). Portanto, pode afirmar-se que a historiografia também exorciza a morte, introduzindo-a no discurso para criar, como no jogo simulador e dissimulador do culto cemiterial dos mortos, a ilusão da sua não existência. 50

Prossegue desenvolvendo a analogia estabelecida por Michel de Certeau entre os cemitérios e as narrações do passado, partindo da etimologia de signo, que remete para túmulo:

Todo o signo funerário, explícita ou implicitamente, remete para o túmulo (signo deriva de sema, pedra tumular), isto é, para uma sobreposição de significantes ... E, neste jogo de negação da morte e da corruptibilidade do tempo, os signos "são assim dados

50 Fernando Catroga, Os passos do homem como restolbo do tempo. Memória e fim do fim da história. (Coimbra: Almedina, 2009), 34. 
em troca do nada segundo uma lei de compensação ilusória pela qual, quanto mais signos temos mais existe o ser e menos o nada" (Jean-Didier, 1997) ... Por isso, o túmulo e o cemitério devem ser lidos como totalidades significantes que articulam dois níveis bem diferenciados: um invisível e outro visível. E as camadas semióticas que compõem este último têm o papel de dissimular a degradação (o tempo) e, em simultâneo, de simular a não morte, transmitindo aos vindouros uma semântica capaz de individuar e de ajudar à re-presentação, ou melhor, à re-presentificação do ontologicamente ausente. É à luz destas características que é lícito falar, a propósito da linguagem cemiterial - tal como do discurso historiográfico -, de uma "poética da ausência"51

A segunda parte da obra dá grande destaque à hermenêutica histórica, mormente à tensão compreensão/explicação que Ricœur transformará em dialética. Embora Catroga faça uma apresentação histórica da temática que extravasa nalguns pontos a exposta por Ricœur, mais concisa a deste, em obras como Temps et Récit ou Du texte à l'action..., adivinha-se o texto ricouriano como matriz intelectual e operatória. O historiador mantém uma posição conivente com a do filósofo francês em toda a amplitude, distanciando-se por aí de parcialismos narrativistas. Ao mesmo tempo que reconhece como pernicioso o repúdio da história política e narrativa e se congratula pelo seu regresso, o próprio tem o cuidado de, no rasto de Ricœur, chamar a atenção para as insuficiências do narrativismo ou

51 Idem, op. cit., 39; cf. Fernando Catroga, Memória, História e Historiografia (Coimbra: Quarteto, 2001), pp. 40-44 e Idem, O Céu da memória. Cemitério romântico e culto cívico dos mortos (Coimbra: Almedina, 2006). A expressão "poética da ausência" é atribuída por Catroga a Ana Anais Gómez, "La sepultura, monumento que constituye la memoria de la vida", in AA. VV., Una Arquitectura para la muerte. I Encontro internacional sobre los cementerios contemporáneos (Sevilha: Junta de Andaluzia, 1995). A citação de Jean-Didier Urbain reporta-se a "Morte", Enciclopédia Einaudi, vol. 36, (Lisboa: Imprensa Nacional-Casa da Moeda, 1997). 
para visões parcelares do campo histórico. Declara o mesmo que "explicar por causas e/ou compreender intenções são atitudes que decorrem do jaez das perguntas feitas às informações retiradas da massa documental que o processo foi selecionando".52 E corrobora a sua afirmação citando Ricœur, de quem retirara o que acabava de afirmar:

Como afirmou Paul Ricœur (1955), "la compréhension n'est donc pas l'opposé de l'explication, elle en est au plus le complément et le contrepartie”. E, sem a obsessão do causalismo nomotético ou do dualismo à Dilthey, quem decide acerca do grau das suas correlações é a problemática. 53

Neste contexto, recorda ainda as várias etapas deste dualismo cognitivo a começar na reação da corrente hermenêutica (de Vico a Humboldt, Droysen, Windelband, Rickert, Simmel, Dilthey, Max Weber) ao cientismo positivista; o apagamento da narrativa e a luta do estruturalismo histórico francês contra a história metódica ou evenemencial, para logo a seguir focar também os retornos da narrativa, protagonizados pelo linguistic turn em reação aos defensores do modelo nomológico e à história económico-social, salientando como marco o artigo de Lawrence Stone. Relembra ainda a autocrítica dos Annales em finais da década de oitenta, que permitiu a recuperação da história política e narrativa, mas também a abertura a outras modalidades e objetos historiográficos, donde se destaca a micro-história e a sua aproximação ao acontecimento, à personagem, à mudança de escala e daí à narrativa.

52 Fernando Catroga, Os passos do homem como restolbo do tempo. Memória e fim do fim da história. (Coimbra: Almedina, 2009), 118.

53 Ibid. 
Sanada a tensão explicação/compreensão por via da dialética ricouriana, Catroga defende um caminho plural para a historiografia contemporânea, nisso se afastando claramente da perspetiva de Fátima Bonifácio. Na senda do filósofo francês, o autor admite a diversidade de métodos explicativos consoante a diversidade dos problemas e dos objetos por estes selecionados, "sem que isso signifique, contudo, a apologia de qualquer ecletismo, ou a busca de sínteses artificiais". ${ }^{54}$ Por conseguinte, em linha com Ricœur, ele vê com bons olhos a utilização de métodos quantitativos ou de leis de outras ciências, se estas ajudarem à explicabilidade de determinada interpretação histórica. Por outro lado, a pluralidade e renovação da historiografia atual mostra que outras interpretações históricas só ficarão comprovadas com o recurso a análises qualitativas, havendo outras que possam apelar mesmo a combinatórias metodológicas. Os debates epistemológicos contemporâneos são avessos a uma conceção unitária de ciência, anulando o conflito tradicional entre ciências da natureza e ciências do espírito. "A hora será de intercâmbio e de colaboração". 55

Outra problemática que merece a atenção de Catroga é a relação entre sujeito e objeto ou entre o historiador e passado. Neste âmbito, tornam-se assaz operativos dois conceitos fundamentais da epistemologia histórica ricœuriana: o conceito de operação historiográfica, axial para Ricœur-Certeau, e o de representância; o primeiro para credibilizar o trabalho do historiador, evitando derivas ficcionistas, revisionistas ou relativistas; o segundo para classificar o estatuto da mediação entre a narrativa e a realidade referenciada, evitando imediatismos positivistas do género adaequatio rei et intellectus.

${ }^{54}$ Idem, op. cit., 120.

55 Ibid. 
Foi precisamente para cortar com as ilusões vindas, quer da crença no mimetismo imediato da representação, quer, no polo oposto, da redução desta à pura ficcionalidade, que Paul Ricœur preferiu falar, já em Temps et récit e, depois, em La Mémoire, l'bistoire et l'oubli, em representância. 56

Por último relembra o autor o papel decisivo de Ricœur, Roland Barthes e Hayden White para a consciencialização epistemológica do estatuto narrativo da história, dizendo que depois dos seus escritos já nenhum historiador pode escamotear a forma narrativa do conteúdo histórico, ou julgar que a sua escrita é extrínseca e separável da verdade descritiva. O pensamento sobre o passado traduz-se em linguagem, em história a contar. Mas, tal como observou Ricœur em crítica a Hayden White, esta consciência exige prudência, para não se cair no extremo do narrativismo, e não se ser levado a esquecer que os textos que o historiador constrói não se esgotam na sua coerência interna ou num arquetípico-estrutural. Logo, considera Catroga "improfícua a adesão acrítica a algumas teses narrativistas". 57 Estamos nos antípodas do que preconizava Fátima Bonifácio.

\section{Conclusão}

A releitura e confronto destes dois historiadores e epistemólogos permite-nos tirar algumas conclusões breves relativamente à apropriação que fazem das teses de Ricour. Ambos leem o autor francês, são influenciados por ele e veiculam a sua hermenêutica histórica nos seus escritos. Não obstante, diferenças assinaláveis os separam. Fátima Bonifácio socorre-se da filosofia ricœuriana

\footnotetext{
56 Idem, op. cit., 127.

57 Idem, op. cit., 128.
} 
para justificar e sustentar uma opção historiográfica e ideológica específica. Com esse intuito, faz uma apropriação apenas parcial e conveniente, ignorando uma parte substancial do todo que lhe era incómoda. Sem embargo, a opção pela história política narrativa não põe em causa o rigor e a excelência das suas investigações e produções historiográficas, como bem o comprovam os estudos de história política do século XIX subsequentes ao ensaio epistemológico por nós analisado e muitos outros que vem publicando. Em linha com o que temos vindo a dizer, hoje a história é plural e admite no seu interior vários modelos explicativos, com a única exigência metodológica de haver acerto entre o objeto, a problemática e o modelo explicativo. Fátima Bonifácio, em função de uma história política que determinou como objeto de estudo, aplica com eficácia e legitimidade o modelo explicativo narrativo, atinente à explicação por razões. Esta opção, sendo coerente, não pode ser criticável. É, ademais, salutar que num país onde a maioria dos historiadores tendeu para as propostas dos Annales, haja quem se ocupe de história política, sem a qual corremos o risco de passar ao lado de grandes acontecimentos transformadores das sociedades. Não sendo um ramo da historiografia que atraia muitos adeptos no nosso país, há ainda uns quantos assinaláveis e dignos de menção: casos de Vasco Pulido Valente, ${ }^{58}$ Rui Ramos, ${ }^{59}$ ou José Pacheco Pereira, ${ }^{60}$ autores de inestimáveis trabalhos de história política.

Catroga, por seu turno, faz uma leitura mais abrangente e ideologicamente descomprometida das teses de Ricœur, as quais se refletem substancialmente nos seus escritos e preleções de Teoria

58 Vasco Pulido Valente, Portugal. Ensaios de História e de Política (Lisboa: Alêtheia, 2009).

59 Rui Ramos (coord.), História de Portugal (Lisboa: Esfera dos livros, 2009).

60 Vide os quatros volumes já publicados por José Pacheco Pereira sobre a icónica figura do comunismo português: Álvaro Cunhal - Uma biografia política (Lisboa: Círculo de Leitores/Temas e Debates, - vol. I 1999; vol. II 2001; vol. III 2005; vol. IV 2016). 
e Filosofia da História. Tem da hermenêutica histórica ricœuriana uma conceção rigorosa e bem assimilada, donde ressumbra não só a admiração pela figura do filósofo, mas também uma extraordinária capacidade para o integrar e diluir nas suas próprias reflexões. Também nas suas alocuções o nome do filósofo francês se ouve amiúde, alcançando, por vezes, o professor e historiador problemáticas ricœurianas ainda não refletidas nos seus livros, caso da teoria do Mesmo, do Outro e do Análogo, desenvolvida por Ricœur em Temps et récit, como caminho intelectual para chegar à criação do conceito de representância. Estamos certos, por isso, de que novas vertentes do pensamento de Ricœur poderão aflorar em futuras publicações de Fernando Catroga. 